\title{
Targeting of ICAM-1 on vascular endothelium under static and shear stress conditions using a liposomal Gd-based MRI contrast agent
}

Leonie EM Paulis ${ }^{1}$, Igor Jacobs ${ }^{1}$, Nynke M van den Akker ${ }^{2}$, Tessa Geelen', Daniel G Molin , Lucas WE Starmans ${ }^{1}$, Klaas Nicolay ${ }^{1}$ and Gustav J Strijkers ${ }^{*}$

\begin{abstract}
Background: The upregulation of intercellular adhesion molecule-1 (ICAM-1) on the endothelium of blood vessels in response to pro-inflammatory stimuli is of major importance for the regulation of local inflammation in cardiovascular diseases such as atherosclerosis, myocardial infarction and stroke. In vivo molecular imaging of ICAM-1 will improve diagnosis and follow-up of patients by non-invasive monitoring of the progression of inflammation.

Results: A paramagnetic liposomal contrast agent functionalized with anti-ICAM-1 antibodies for multimodal magnetic resonance imaging (MRI) and fluorescence imaging of endothelial ICAM-1 expression is presented. The ICAM-1-targeted liposomes were extensively characterized in terms of size, morphology, relaxivity and the ability for binding to ICAM-1-expressing endothelial cells in vitro. ICAM-1-targeted liposomes exhibited strong binding to endothelial cells that depended on both the ICAM-1 expression level and the concentration of liposomes. The liposomes had a high longitudinal and transversal relaxivity, which enabled differentiation between basal and upregulated levels of ICAM-1 expression by MRI. The liposome affinity for ICAM-1 was preserved in the competing presence of leukocytes and under physiological flow conditions.

Conclusion: This liposomal contrast agent displays great potential for in vivo MRI of inflammation-related ICAM-1 expression.
\end{abstract}

Keywords: Molecular MRI, Liposome, ICAM-1, Endothelium, Leukocyte, Shear stress

\section{Background}

The vascular endothelium plays an essential role in the regulation of the inflammatory phases of atherosclerosis and related cardiovascular complications such as myocardial infarction and stroke [1-3]. In response to local proinflammatory stimuli, the endothelial expression of cell adhesion molecules is upregulated to mediate interactions with leukocytes circulating in the blood $[4,5]$. This allows for leukocyte adhesion to the endothelium, followed by extravasation of leukocytes through the endothelial cell layer to the site of inflammation.

\footnotetext{
* Correspondence: g.j.strijkers@tue.nl

1 Biomedical NMR, Department of Biomedical Engineering, Eindhoven University of Technology, PO Box 513, 5600 MB, Eindhoven, the Netherlands Full list of author information is available at the end of the article
}

Intercellular adhesion molecule-1 (ICAM-1), a transmembrane immunoglobulin protein that is predominantly expressed on endothelial cells, is of major importance in leukocyte recruitment [6]. Upregulation of ICAM-1 contributes to stable binding of leukocytes and facilitates their transmigration by rearranging the endothelial cytoskeleton and lowering the strength of endothelial cell junctions [7]. Non-invasive in vivo molecular imaging of endothelial ICAM-1 expression could therefore provide valuable insights in the progression of cardiovascular disease-related inflammation to improve diagnosis and treatment [8].

Molecular imaging employs sophisticated contrast agents that combine high affinity targeting ligands with imaging labels for in vivo visualization of biological processes at the cellular and molecular level. In this study, we introduce a novel liposomal contrast agent functionalized

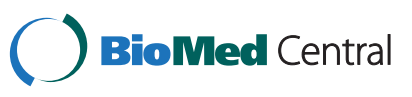


with anti-ICAM-1 (aICAM-1) antibodies for sensitive multimodal magnetic resonance imaging (MRI) and fluorescence imaging of endothelial ICAM-1 expression. MRI enables in vivo high-resolution imaging of ICAM-1 expression in an anatomical context, whereas ex vivo fluorescence microscopy can be used to study the spatial distribution of the liposomes at the tissue and cellular level [9]. Because of the relatively large diameter of the liposomes (100-150 nm), passive extravasation from the blood is expected to be minimal and liposomes will be largely confined to the blood pool, which facilitates the detection of intravascular targets such as ICAM-1.

The binding of ICAM-1 targeted liposomal contrast agents to endothelial cells was extensively studied in vitro. Liposomes were characterized with respect to their size, morphology, longitudinal and transversal relaxivity, and the average number of targeting ligands per liposome was optimized regarding sensitive MRI and fluorescence detection of endothelial ICAM-1 expression. Importantly, this study focused on various aspects that might negatively affect the binding of liposomes to ICAM-1-expressing endothelial cells in vivo. In the challenging intravascular environment, ICAM-1 targeted nanoparticles have to compete with circulating leukocytes for binding to ICAM-1 [4,6]. Additionally, blood flow creates endothelial wall shear stress, which shortens the interaction time of nanoparticles with ICAM-1 and imposes hydrodynamic forces on adherent particles, which may result in their detachment $[10,11]$. Under these conditions, a high binding affinity of ICAM-1-targeted liposomes to the endothelium is crucial to enable in vivo imaging of ICAM-1. To address these issues, liposome binding was investigated in vitro in the presence of leukocytes and under physiologically relevant shear stress conditions.

\section{Results}

\section{Liposome characterization}

Antibodies (Ab) were modified using $N$-succinimidyl $S$ acetylthioacetate (SATA) and conjugated to liposomes containing Mal-PEG-DSPE by sulfhydryl-maleimide coupling. Significant binding of antibodies to liposomes was observed for all Ab:SATA ratios used (Table 1). Paramagnetic liposomes were successfully functionalized with murine aICAM-1 or isotype matched non-specific IgG. In Figure 1a representative dynamic light scattering (DLS) spectra are shown of the size distribution of nonfunctionalized liposomes (L), IgG L and aICAM-1 L, both prepared with antibodies modified with an 80-fold excess of SATA. A single dominant peak was observed for all liposome preparations, indicative of a homogeneous liposome size. Moreover, antibody conjugation did not significantly alter the mean diameter of aICAM-1 L and IgG L compared to L (Table 1).
To study liposome morphology in higher detail, cryogenic transmission electron microscopy (cryoTEM) was performed (Figure 1b-d). Both non-functionalized and antibodyconjugated liposome suspensions primarily consisted of unilamellar, spherical liposomes, with sizes that were in line with the DLS data.

Paramagnetic liposomes displayed MRI longitudinal and transversal relaxivities of approximately $3.0 \mathrm{mM}^{-1} \mathrm{~s}^{-1}$ and $20-55 \mathrm{mM}^{-1} \mathrm{~s}^{-1}$ at $9.4 \mathrm{~T}$, respectively (Table 1 ). The relaxivities were not significantly affected by liposome functionalization with aICAM-1 or IgG antibodies, though there was a large variation in the observed $r_{2}(p>0.05$, aICAM$1 \mathrm{~L}(1: 80)$ and IgG L (1:80) vs. L).

\section{Binding of liposomes to ICAM-1}

The ability of aICAM-1 L, prepared using antibodies modified with an 8- to 80-fold excess of SATA, to bind to ICAM-1 was studied using bEnd.5 endothelial cells expressing ICAM-1 at basal (non-activated) or upregulated (TNF $\alpha$-activated) levels. Non-activated and activated cells incubated with $\mathrm{L}$ and various preparations of IgG $\mathrm{L}$ had a low NIR-fluorescence intensity $(n=4$ per group; not shown). In contrast, binding of aICAM-1 L significantly increased the fluorescence of activated cells up to 100-fold as compared to IgG L. Highest fluorescence intensities, indicative of the highest degree of binding, were observed for liposomes functionalized with aICAM-1 antibodies that were modified with an 80-fold excess of SATA (mean fluorescence intensity $=39.0 \pm 4.6, \mathrm{p}<0.05$ vs. all groups) (Figure 2a). In addition, the fluorescence of non-activated cells was exclusively enhanced by aICAM- $1 \mathrm{~L}$ when prepared with an 80-fold excess of SATA (mean fluorescence intensity $=3.1 \pm 0.9 ; \mathrm{p}<0.05$ vs. IgG L).

In Figure $2 b$, representative CLSM images illustrate the cellular distribution of aICAM-1 L and IgG L (Ab:SATA = 1:80). The aICAM-1 L were mainly associated with the cell membrane for both activated and non-activated cells. In accordance with the fluorescence intensity measurements (Figure 2a), abundant binding of aICAM-1 L to activated cells (high ICAM-1 expression) was observed compared to low binding to non-activated cells (basal ICAM-1 expression). Positive secondary labeling of the liposome-associated antibodies with fluorescent goat-antirat antibodies revealed that the aICAM-1 moieties on liposomes were available on the outside of the cell membrane, thereby confirming their membrane-bound location (Additional file 1: Figure S1). Liposomal fluorescence was frequently observed in distinct spots (diameter $=2.5 \pm$ $0.3 \mu \mathrm{m}$, measurement of 30 spots in 3 images) that were larger than the size of individual liposomes. In contrast, CLSM images showed low intracellular accumulation of IgG L, which could only be detected at high laser power. The cellular distribution of aICAM-1 L and IgG L was independent on the antibody to SATA modification ratio. 
Table 1 Properties of L, IgG L and aICAM-1 L

\begin{tabular}{|c|c|c|c|c|}
\hline & antibody coupling [\%] & hydrodynamic diameter [nm] & $r_{1}\left[\mathrm{mM}^{-1} \mathrm{~s}^{-1}\right]$ & $r_{2}\left[\mathrm{mM}^{-1} \mathrm{~s}^{-1}\right]$ \\
\hline \multicolumn{5}{|l|}{ NIR-liposomes } \\
\hline $\mathbf{L}$ & $2.5 \pm 2.8^{\mathrm{a}, \mathrm{b}}$ & $130 \pm 6^{b}$ & $3.3 \pm 0.2^{b}$ & $39 \pm 1^{b}$ \\
\hline $\lg G \operatorname{L}(1: 8)^{c}$ & $64 \pm 27^{d}$ & $140 \pm 4$ & 2.9 & 22 \\
\hline IgG L (1:20) & $54 \pm 18^{d}$ & $140 \pm 9$ & 2.8 & 23 \\
\hline IgG L (1:40) & $89 \pm 46^{d}$ & $132 \pm 10$ & 3.2 & 46 \\
\hline IgG L (1:80) & $84 \pm 21^{d}$ & $134 \pm 5$ & $2.7 \pm 0.4$ & $38 \pm 6$ \\
\hline alCAM-1 L (1:8) & $52 \pm 28^{d}$ & $137 \pm 9$ & 2.9 & 27 \\
\hline aICAM-1 L (1:20) & $66 \pm 20^{d}$ & $133 \pm 16$ & 3.3 & 30 \\
\hline aICAM-1 L (1:40) & $88 \pm 24^{d}$ & $156 \pm 0^{d}$ & 3.1 & 89 \\
\hline aICAM-1 L (1:80) & $83 \pm 9^{d}$ & $141 \pm 2$ & $2.7 \pm 0.4$ & $53 \pm 16$ \\
\hline \multicolumn{5}{|c|}{ Rhodamine-liposomes } \\
\hline $\mathbf{L}$ & $-0.8 \pm 0.8^{a}$ & $133 \pm 5$ & $4.2 \pm 0.8$ & $54 \pm 8$ \\
\hline aICAM-1 L (1:80) & $98 \pm 4^{d}$ & $163 \pm 2$ & $3.3 \pm 0.1$ & $53 \pm 15$ \\
\hline
\end{tabular}

Liposomes contained either a NIR or a rhodamine fluorophore. $n=1-5 ;{ }^{a}$ baseline value indicative for the inaccuracy of the protein assay; ${ }^{b}$ mean \pm SEM; ${ }^{c}(1: x)$ the applied molar ratio of Ab: SATA; ${ }^{d}=p<0.05$ vs. L, ANOVA with LSD correction for NIR-liposomes and $t$-test for rhodamine-liposomes.

Above results showed that aICAM-1 L prepared with an antibody to SATA modification ratio of 1:80 had the highest level of association to ICAM-1 expressing bEnd. 5 cells. These liposomes had the unique ability to identify both basal and upregulated levels of ICAM-1 expression $(\mathrm{p}<0.05)$. The liposome formulation with a 1:80 antibody to SATA ratio was therefore used in further experiments described below.

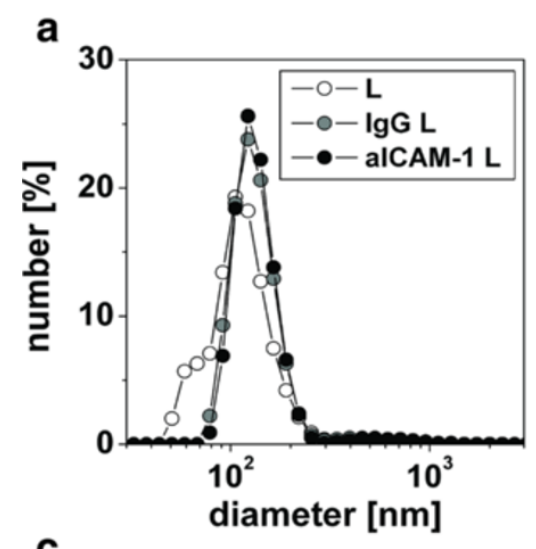

C

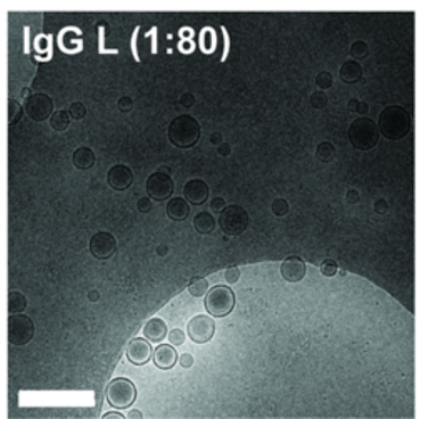

b

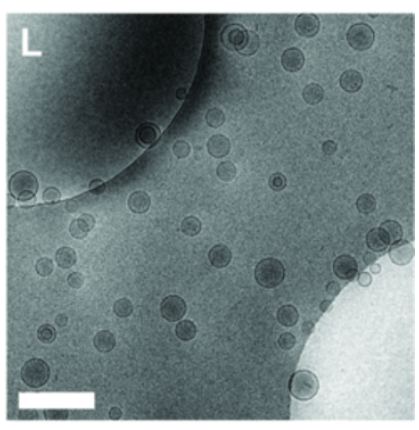

d

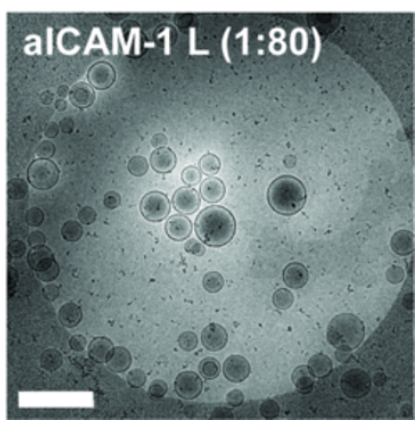

Figure 1 Characterization of the liposomes by DLS and cryoTEM. (a) Representative DLS size distributions of $L$, IgG $L(A b: S A T A=1: 80)$ and alCAM-1 L (Ab:SATA = 1:80) that were prepared from a single batch of liposomes. The three types of liposomes display a similar narrow size distribution. CryoTEM was used to study the morphology of (b) $L$, (c) IgG $L$ (Ab:SATA =1:80) and (d) alCAM-1 L (Ab:SATA = 1:80). Lipid suspensions were mainly composed of single unilamellar liposomes. Scale bar $=500 \mathrm{~nm}$. 


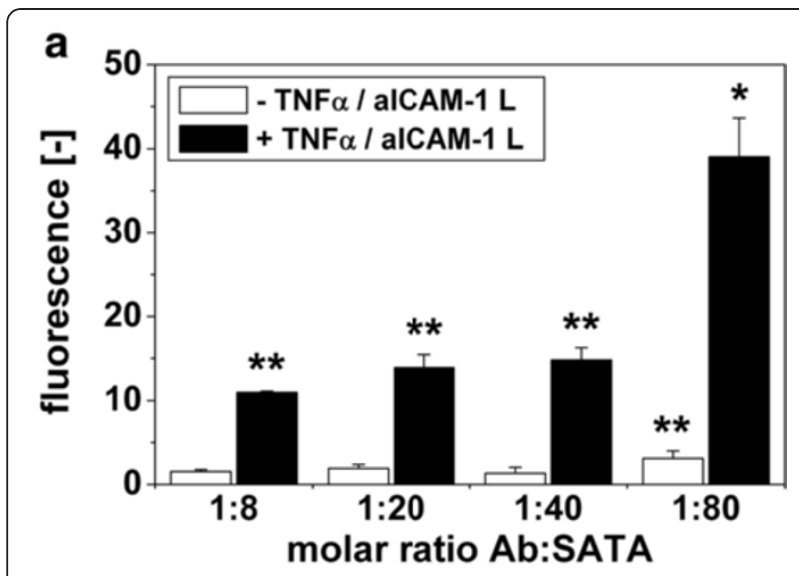

b
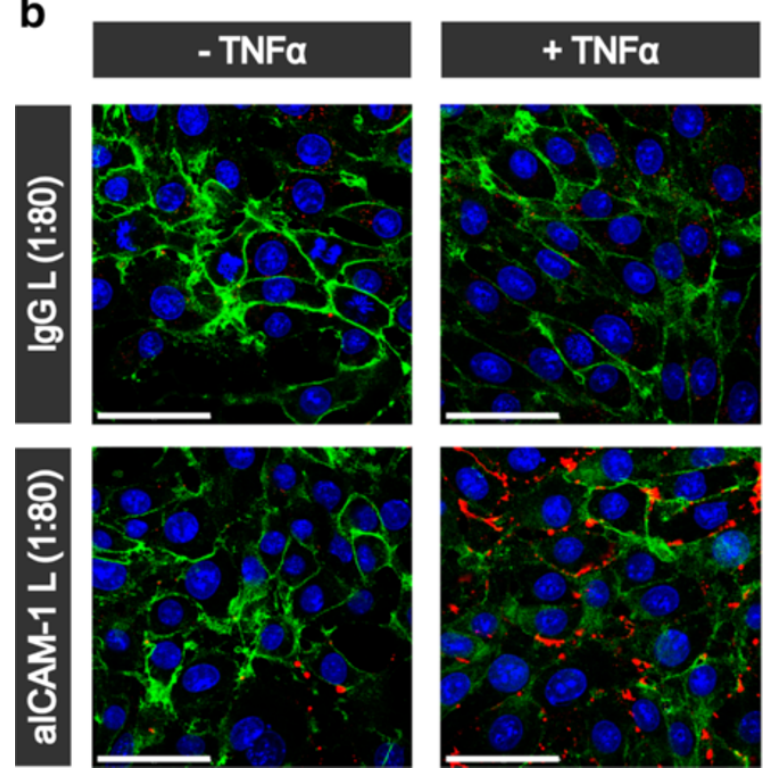

Figure 2 Binding of alCAM-1 L to non-activated and TNFaactivated bEnd.5 cells. (a) Cellular NIR fluorescence intensity of non-activated and TNFa-activated bEnd.5 cells after $2 \mathrm{~h}$ incubation at $37^{\circ} \mathrm{C}$ with alCAM-1 L, prepared using different Ab:SATA ratios, quantified with FACS. Data were corrected for cellular fluorescence after incubation with $L$ and reflect the increase in fluorescence by alCAM-1 conjugation. Application of lgG $L$ did not lead to an increase in fluorescence intensity (not shown). ${ }^{*}=p<0.05$ vs. all groups, ${ }^{* *}=p<0.05$ vs. IgG L, ANOVA with Bonferroni correction. $n=3-4$. (b) CLSM images illustrating the cellular distribution of alCAM-1 L (Ab:SATA = 1:80) and IgG L (Ab:SATA = 1:80) (red). The cell membrane was labeled with CD31 (green) and cell nuclei were counterstained with DAPI (blue). Laser power 488 nm: 25\%, $780 \mathrm{~nm}$ : 4\%, 633 nm, IgG L: 50\%, alCAM-1 L/-TNFa: 10\% and alCAM-1 L/+TNFa: $5 \%$. Scale bar $=50 \mu \mathrm{m}$.

\section{Liposome concentration-dependence of ICAM-1 binding}

The binding of liposomes to endothelial cells as function of the concentration of liposomes in the incubation medium was determined at $4{ }^{\circ} \mathrm{C}$ to minimize liposome internalization and ICAM-1 recycling for accurate evaluation of the liposomal ICAM-1 binding interactions.
Under these conditions, the NIR-fluorescence intensity of TNF $\alpha$-activated bEnd. 5 cells depended on the concentration of aICAM-1 L in the incubation medium (Figure 3a), but not on the concentration of $\operatorname{IgG~L}$ (Figure 3b). The mean fluorescence intensity of both activated and non-activated endothelial cells linearly related to the concentration of aICAM-1 L $\left(R^{2}=0.99\right)$, indicating that ICAM-1 binding was not saturated within the concentration range studied (Figure 3c). In contrast, application of IgG L at concentrations up to 2 $\mathrm{mM}$ lipid did not result in significant binding to endothelial cells (Figure 3c). Importantly, the binding of aICAM-1 L to activated cells was significantly higher than to non-activated cells (linear slope of 4.0 versus 1.0), proving that the association of aICAM-1 L was also related to the level of ICAM-1 expression.

The minimal aICAM-1 L concentration required to detect upregulated levels of ICAM-1 expression on activated cells using fluorescence activated cell sorting (FACS) was $0.125 \mathrm{mM}$ lipid, whereas $0.5 \mathrm{mM}$ lipid was needed to

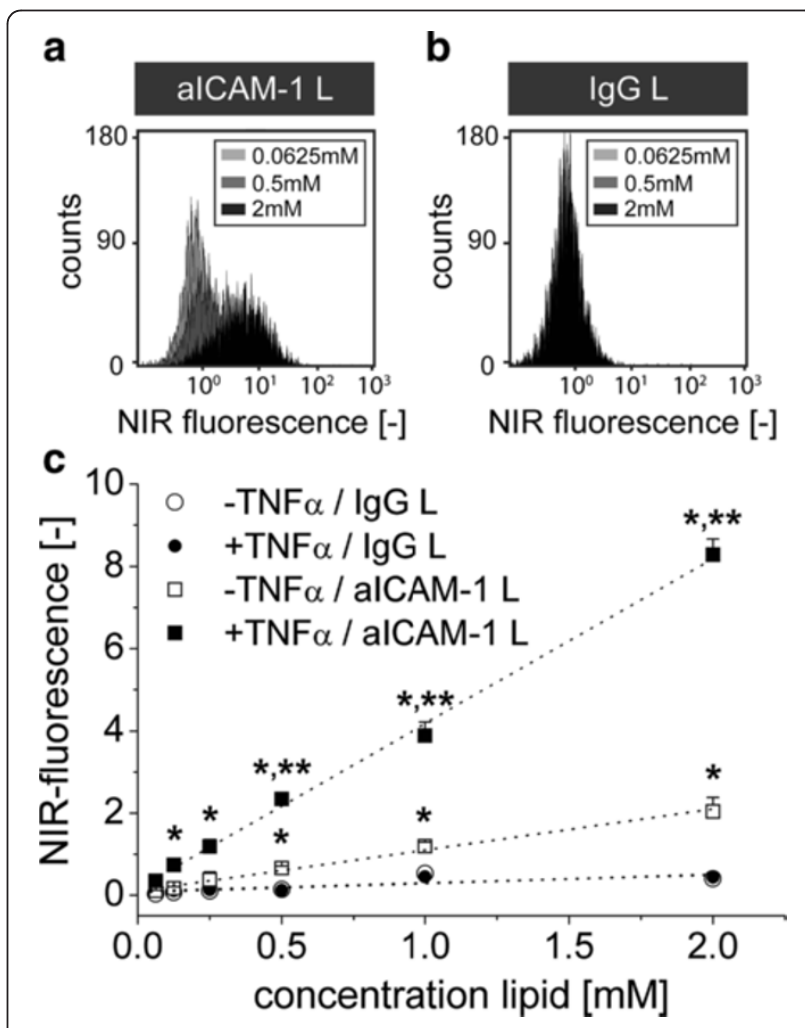

Figure 3 Binding of alCAM-1 L and IgG $L$ to bEnd.5 cells with varying lipid concentration. Representative FACS spectra of NIR fluorescence of TNFa-activated bEnd.5 cells after 30 min incubation at $4{ }^{\circ} \mathrm{C}$ with (a) alCAM-1 $L$ and (b) $\lg G L$ at different liposome concentrations. (c) Mean fluorescence intensity of non-activated and TNFa-activated bEnd. 5 cells after incubation with $\lg G$ or alCAM-1 $L$ at liposome concentrations varying from $0.0625-2 \mathrm{mM}$ lipid. ${ }^{*}=p<0.05$ vs. IgG $L,{ }^{* *}=p<0.05$ vs. alCAM-1 L/-TNFa, t-test. $n=3$ for alCAM-1 $L, n=1$ for $\lg G \mathrm{~L}$. 
identify the basal ICAM-1 expression levels on nonactivated cells ( $\mathrm{p}<0.05$ aICAM-1 L vs. IgG L). Cellular fluorescence was significantly higher for activated cells as compared to non-activated cells when incubated with aICAM-1 L at lipid concentrations of $0.25 \mathrm{mM}$ and higher.

\section{MRI detection sensitivity}

To enable MR-imaging of ICAM-1 expression, paramagnetic aICAM-1 L must specifically and significantly decrease the MR relaxation time parameters. Representative $\mathrm{T}_{1}$ and $\mathrm{T}_{2}$ maps obtained at 9.4 $\mathrm{T}$ (Figure 4a) demonstrated the ability of aICAM-1 L to reduce the relaxation times of cells compared to native cells or those incubated with control liposomes (IgG L or L). This can be recognized from the much brighter color in pellet number 4 . From these $T_{1}$ and $T_{2}$ maps, the mean cellular $R_{1}$ and $R_{2}$ were calculated (Figure $4 b, c$ ). The $R_{1}$ and $R_{2}$ of TNF $\alpha-$ activated cells were significantly increased by aICAM-1 L $\left(1.8 \pm 0.1 \mathrm{~s}^{-1}\right.$ and $78 \pm 4 \mathrm{~s}^{-1}$, respectively) with respect to controls. Importantly, a significant (but smaller) increase in $R_{1}$ and $R_{2}$ was also observed for non-activated cells incubated with aICAM-1 L $\left(0.75 \pm 0.07 \mathrm{~s}^{-1}\right.$ and $39 \pm 4 \mathrm{~s}^{-1}$, respectively). Application of control liposomes (IgG L and $\mathrm{L})$ did not alter the cellular $\mathrm{R}_{1}$ or $\mathrm{R}_{2}(\mathrm{p}>0.05)$. Importantly, aICAM-1 L enabled MRI to distinguish between cells with basal and upregulated levels of ICAM-1 expression $(\mathrm{p}<0.05)$.
Figure $4 \mathrm{~d}$ illustrates that the increase in the relaxation rates of cells incubated with aICAM-1 L was consistent with a significant association of gadolinium with activated cells $(0.84 \pm 0.18 \mathrm{mM} \mathrm{Gd})$ and non-activated cells $(0.20 \pm 0.08 \mathrm{mM} \mathrm{Gd})$ compared to control liposomes. Interestingly, the effective relaxivities $r_{1}$ and $r_{2}$ of cells incubated with aICAM-1 L, which were estimated from the MR-relaxation rates and gadolinium concentrations, were also dependent on the ICAM-1 expression level. The $\mathrm{r}_{1}$ improved from $1.2 \pm 0.2 \mathrm{mM}^{-1} \mathrm{~s}^{-1}$ to $1.7 \pm 0.5 \mathrm{mM}^{-1} \mathrm{~s}^{-1}$ for cells with basal and upregulated ICAM-1 expression, respectively, whereas the $r_{2}$ increased from $42 \pm 6 \mathrm{mM}^{-1} \mathrm{~s}^{-1}$ to $103 \pm 16 \mathrm{mM}^{-1} \mathrm{~s}^{-1}(\mathrm{p}<0.05)$. We hypothesize that the increased cellular relaxivity for upregulated levels of ICAM-1 is due to increased immobilization of the liposomes on the cell membrane by steric hindrance.

\section{Competition from leukocytes}

In vivo imaging of ICAM-1 expression on inflamed endothelium by aICAM-1 L may be hampered by the presence of circulating leukocytes, which compete with liposomes for binding to ICAM-1. Additionally, leukocytes might phagocytose liposomes, making them unavailable for binding to endothelial ICAM-1. To investigate these interactions in vitro, endothelial cells were coincubated with liposomes and leukocytes that constitutively express CD11b and CD18 (Additional file 2: Figure $\mathrm{S} 2$ ), a receptor pair which binds ICAM-1.
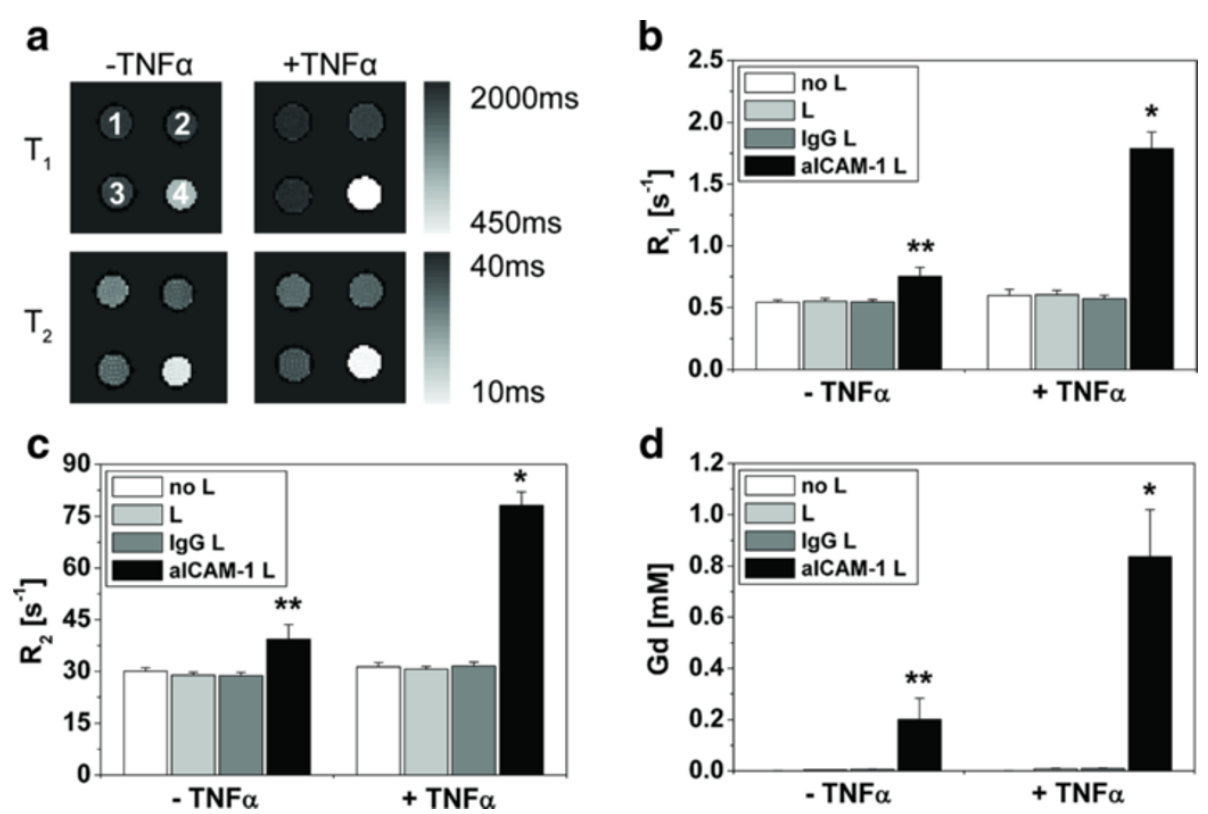

Figure 4 MRI characterization of bEnd. 5 cells incubated with non-targeted and ICAM- 1 targeted liposomes. (a) Representative $T_{1}$ and $T_{2}$ maps of non-activated and TNFa-activated bEnd. 5 cells, incubated for $2 \mathrm{~h}$ at $37^{\circ} \mathrm{C}$ with 1) no liposomes, 2) L, 3) lgG L and 4) alCAM-1 L. Cellular (b) $R_{1}$ and (c) $R_{2}$ measured at 9.4 T. (d) Concentration of gadolinium associated with bEnd.5 cells determined with ICP-MS. ${ }^{*}=p<0.05$ vs. all groups, ${ }^{* *}=p<0.05$ vs. all non-activated groups, ANOVA with Bonferroni correction. $n=4$. 
The FACS scatter plots in Figure $5 \mathrm{a}-\mathrm{c}$ reveal that the NIR-fluorescence of TNF $\alpha$-activated endothelial cells incubated with aICAM-1 L slightly decreased with increasing concentration of leukocytes. More extensively, in Figure $5 \mathrm{~d}$ the mean fluorescence intensity originating from aICAM-1 L and IgG L bound to either activated or non-activated endothelial cells is shown for increasing leukocyte concentrations. A moderate, but significant decline in endothelial fluorescence from $76.5 \pm 3.0$ (no leukocytes) to $65.2 \pm 1.9\left(2 \times 10^{5}\right.$ leukocytes $\left./ \mathrm{ml}\right)$ and $55.6 \pm 1.5$ (1x10 ${ }^{6}$ leukocytes/ml) was observed for aICAM-1 L, indicating that leukocytes indeed reduced the association of aICAM-1 L with activated endothelium. Nevertheless, the fluorescence of activated endothelial cells was strongly enhanced by aICAM-1 L compared to IgG L, regardless of the presence of leukocytes $(p<0.05)$. The ability of aICAM-1 L to bind to non-activated endothelial cells was not compromised by leukocytes, as the endothelial fluorescence was independent on the concentration of leukocytes in this case (Figure 5d).

Importantly, leukocytes exhibited massive accumulation of IgG L and aICAM-1 L, as illustrated in Figure 5e, in which the mean leukocyte fluorescence intensity is shown. Upon incubation with IgG L, the fluorescence of leukocytes was increased 135-fold compared to endothelial cells (compare Figure 5d and Figure 5e). Additionally, leukocyte fluorescence was significantly higher when cells were incubated with aICAM-1 L $(116 \pm 3)$ compared to IgG L $(95.0 \pm 0.8)$, which is in accordance with the expression of ICAM- 1 by leukocytes (Additional file 2: Figure S2). The association of liposomes with leukocytes was independent of the presence of endothelial cells, both for non-activated and activated endothelial cells.

\section{Liposomal ICAM-1 binding under shear stress conditions}

The in vivo binding of aICAM-1 L to vascular endothelium requires fast and strong interactions with ICAM-1 to resist the continuous shear stress generated by blood flow. Therefore, the binding potential of aICAM-1 L was studied under physiologically relevant wall shear stress values up to $0.5 \mathrm{~Pa}$ in vitro [12]. Fluorescence microscopy images of TNF $\alpha$-activated endothelial cells incubated with $\mathrm{L}(0 \mathrm{~Pa})$ and aICAM-1 L $(0,0.25$ and $0.5 \mathrm{~Pa})$ are shown in Figure 6a. Fluorescence originating from binding of aICAM-1 L was detected at all applied shear stress values, whereas no significant fluorescence was observed after application of L. However, shear stress elevation resulted in a reduction of the fluorescence of

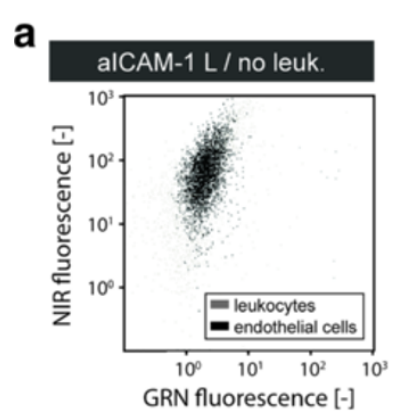

d

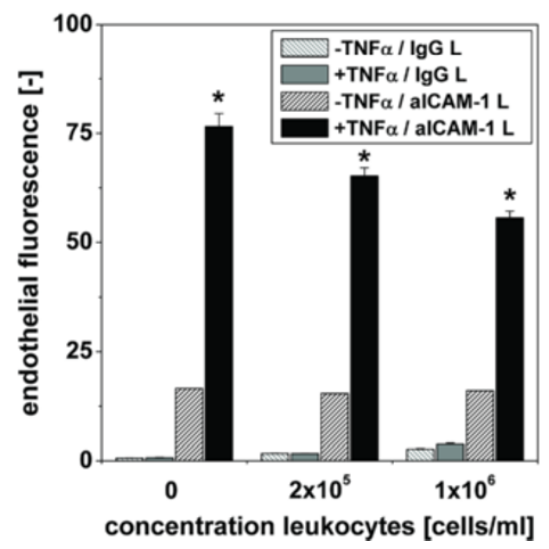

\section{b}
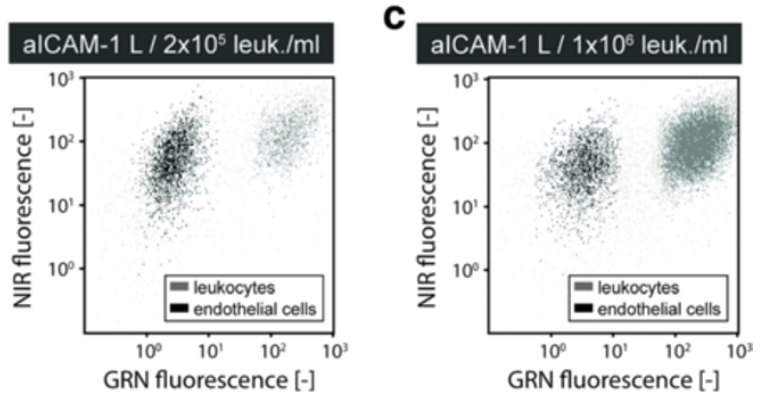

e

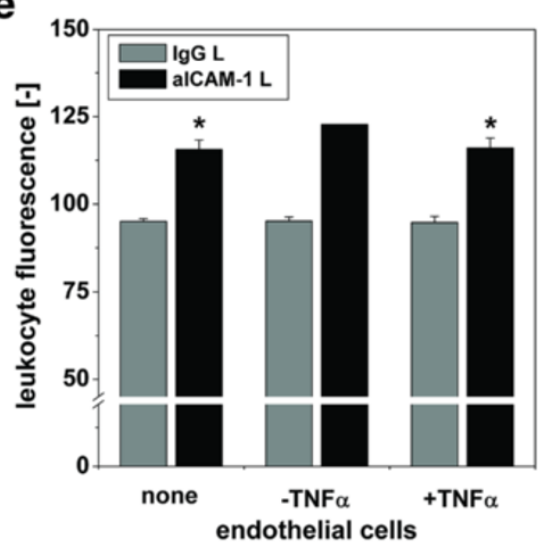

Figure 5 Binding of alCAM-1 L to bEnd.5 in the competing presence of leukocytes. Non-activated and TNFa-activated bEnd.5 cells incubated for $2 \mathrm{~h}$ at $37^{\circ} \mathrm{C}$ with lgG $\mathrm{L}$ or alCAM-1 $\mathrm{L}$ in the presence of $0,2.5 \times 10^{5}$ or $1 \times 10^{6}$ leukocytes $/ \mathrm{ml}$ medium. (a-c) Typical FACS scatter plots of liposomal NIR-fluorescence vs. GRN (green) fluorescence to distinguish TNFa-activated bEnd.5 cells from RAW cells labeled with calcein (green). (d) Endothelial NIR fluorescence intensity. ${ }^{*}=p<0.05$ vs. all groups, ANOVA with Bonferroni correction. (e) Leukocyte NIR fluorescence intensity. * $=p<0.05$ vs. IgG L, ANOVA with Bonferroni correction. $n=3$, except for alCAM-1 L/-TNFa $n=1$. 


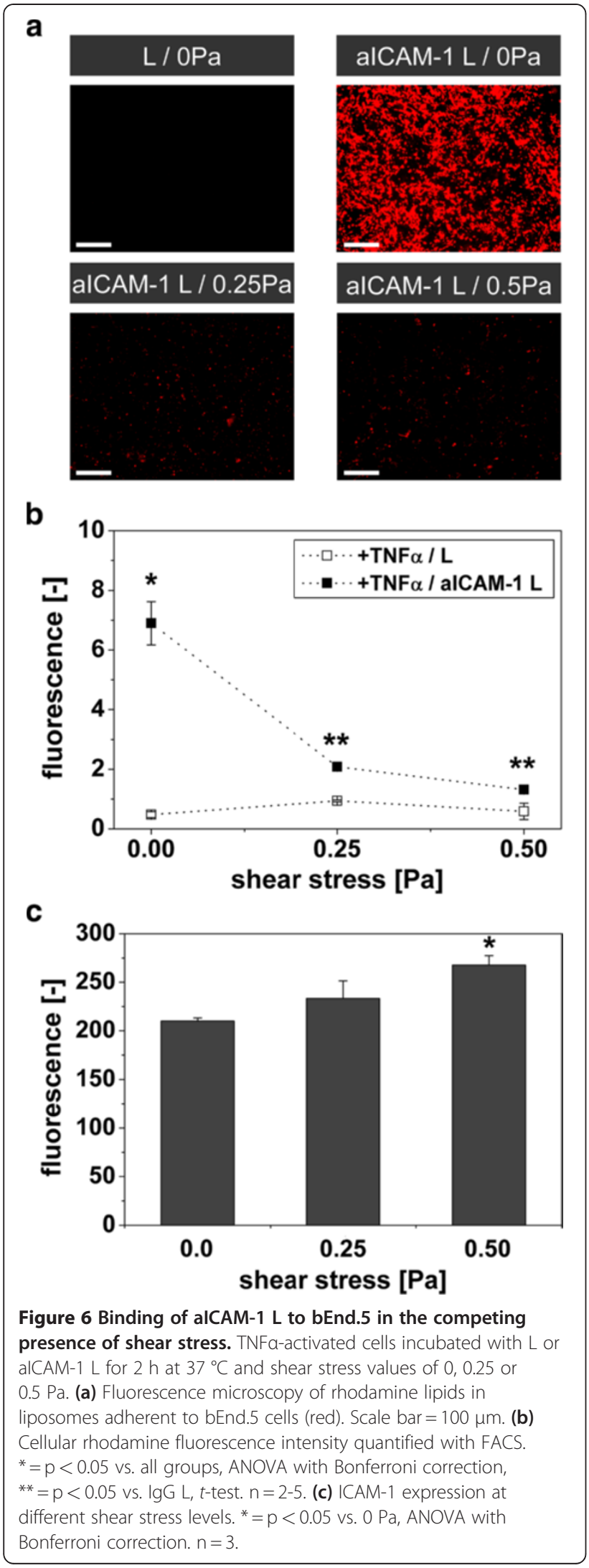

aICAM-1 L, indicative of decreased binding to ICAM-1, compared to static conditions.

After harvesting the cells from the flow chamber, the fluorescence intensity was quantified by FACS (Figure 6b). The application of flow reduced the ability of aICAM-1 L to adhere to ICAM-1 on endothelial cells, as evidenced by a significant decrease in cellular fluorescence from $6.9 \pm 0.7$ $(0 \mathrm{~Pa})$ to $2.1 \pm 0.1(0.25 \mathrm{~Pa})$ and $1.3 \pm 0.1(0.5 \mathrm{~Pa})$. A confounding factor could be that wall shear stress altered the ICAM-1 expression levels. Fluorescent evaluation of ICAM-1 expression showed that ICAM-1 expression levels were increased at shear stress levels of $0.25 \mathrm{~Pa}$ and $0.5 \mathrm{~Pa}$ (Figure 6c), in agreement with previous findings [13,14]. Therefore, the reduction of nanoparticle binding under flow conditions is somewhat higher than the numbers indicate. Nevertheless, the binding of aICAM-1 L to endothelial cells remained significantly higher than of $\mathrm{L}$ at both shear stress levels.

\section{Discussion}

Excessive recruitment of leukocytes to sites of atherosclerosis, myocardial infarction or stroke is implicated in adverse disease progression [15,16]. Clinical treatment decisionmaking might therefore substantially benefit from in vivo imaging readouts of the local inflammatory status. The in vivo MR-imaging of cell adhesion molecules expressed on inflamed vascular endothelium is of particular interest, considering their crucial role in mediating leukocyte extravasation [4]. Previous studies have demonstrated that targeted iron-oxide-based MR-contrast agents are able to

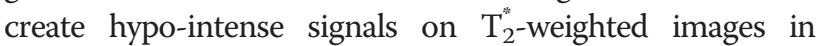
regions of VCAM-1 or P-selectin expression in mouse models of atherosclerosis and brain inflammation [17-19]. Alternatively, the use of targeted Gd-based probes, which create signal hyperenhancement on $\mathrm{T}_{1}$-weighted images, has been explored as well [20-22]. Choi et al. used antiICAM-1 antibodies decorated with Gd-DTPA moieties to highlight muscular inflammation on in vivo MRI, whereas Sipkins et al. performed ex vivo MRI to visualize brain inflammation using paramagnetic liposomes $[20,21]$. In this study, a novel paramagnetic ICAM-1-targeted liposomal contrast agent was designed and, importantly, its interaction with ICAM-1 was studied in vitro under conditions that mimic the challenging environment encountered in the circulation.

Liposomes containing Gd-DOTA-DSPE previously have been characterized with respect to their MRI properties at 1.4 $\mathrm{T}$, which is close to a clinical field strength of $1.5 \mathrm{~T}$ [23]. At 1.4 T, Gd-DOTA-DSPE liposomes have a high longitudinal relaxivity compared to frequently used Gd-DTPABSA liposomes, which is caused by improved water access to Gd by the use of a small linker between DSPE and DOTA as well as by the different exchange dynamics of water bound to the Gd ion that is much faster for the tetra- 
carboxylate DOTA ligand than for the bis-carboxoamide linear DTPA ligand [23,24]. A high longitudinal relaxivity will facilitate sensitive detection of the Gd-DOTA-DSPE liposomes. At the high preclinical field strength used in this study $(9.4 \mathrm{~T})$ one cannot fully exploit this high longitudinal relaxivity. Nevertheless, relaxivity numbers are expressed in terms of relaxivity per $\mathrm{Gd}$ atom and the very high payload of $\mathrm{Gd}\left(\sim 10^{5} \mathrm{Gd}\right.$ per liposome) results in much higher relaxivity values per nanoparticle and thus sensitive detection on $\mathrm{T}_{1}$-weighted images [25]. A possible drawback of the use of these liposomes is the enhanced $r_{2} / r_{1}$ ratio at $9.4 \mathrm{~T}$, which might introduce a considerable $\mathrm{T}_{2}$-weighting in the images. However, by carefully choosing the MR-imaging parameters, $T_{2}$ effects can be minimized to make optimal use of the $\mathrm{T}_{1}$-lowering properties of liposomes.

The binding of liposomes to ICAM-1 expressing endothelial cells was optimized by improving the coupling of aICAM-1 antibodies by increasing the extent of antibody thiolation. The antibody-coupling efficacy was enhanced by 30-60\% using an 80-fold excess of SATA compared to an 8fold excess. The 1:80 antibody to SATA modification ratio resulted in a liposomal antibody density of 960-1200 Ab/ $\mu^{2}$, which compares well to recent studies using ICAM-1 targeted polystyrene beads or ultrasound microbubbles $[11,26,27]$. The ability of aICAM- $1 \mathrm{~L}$ to adhere to ICAM-1 expressing endothelial cells was not compromised by the extensive antibody thiolation (Figure 2a). Furthermore, the association of aICAM-1 L with endothelial ICAM-1 varied linearly with the concentration of liposomes (Figure 3c) and did not saturate within a physiologically relevant range (up to $2 \mathrm{mM}$ lipid). This agrees with earlier studies using fluorescent liposomes where ICAM-1 binding was only saturated at higher liposome concentrations (5 to $12 \mathrm{mM}$ lipid) $[28,29]$. Importantly, the binding of aICAM-1 L was dependent on the level of ICAM-1 expression on the endothelial cell membrane (Figures 2a, 3c), which is encouraging for the use of aICAM-1 L for quantitative in vivo MRimaging of ICAM-1.

The sensitivity of MRI at 9.4 T was sufficient to differentiate between basal and upregulated levels of ICAM-1 expression in vitro based on the MR relaxation rates of endothelial cells after binding of paramagnetic aICAM-1 L (Figure $4 \mathrm{~b}, \mathrm{c})$. Interestingly, the contribution of aICAM-1 L to the cellular $R_{1}$ was larger than to the $R_{2}$, despite the high $r_{2} / r_{1}$ ratio of liposomes in buffer at $9.4 \mathrm{~T}$. This pronounced effect of aICAM-1 L on endothelial cell $\mathrm{R}_{1}$ will facilitate the detection of ICAM-1 expression on vascular endothelium in vivo with $\mathrm{T}_{1}$-weighted MRI. Additionally, this finding indicated that the longitudinal relaxivity of aICAM-1 L could be fully exploited and was not restricted by limited water exchange as a result of internalization and subsequent compartmentalization of liposomes into endosomes, as was previously observed for $\alpha_{v} \beta_{3}$-targeted liposomes [30,31]. CLSM indeed showed that aICAM-1 L were not internalized, but were mainly bound to the extracellular side of the cell membrane (Additional file 1: Figure S1) - a distinct advantage to other ICAM-1 specific nanoparticles [29,32,33]. Previously, though, Mastrobattista et al. have shown internalization of ICAM-1 targeted liposomes by human lung epithelial cells, indicating that the human ICAM-1 receptor is able to internalize liposomes [29]. Moreover, Muro et al. have performed extensive studies on the internalization pathway of ICAM-1 targeted nanometer and micrometer sized fluorescent particles to clarify the exact mechanism for ICAM-1 mediated internalization in endothelial cells [32-34]. The observed lack of internalization of aICAM-1 L in our study could also be related to differences in the condition of bEnd.5 endothelial cells compared to human umbilical vein or lung epithelial cells used in other studies, thereby resulting in an inability to internalize aICAM-1 L through cell-adhesionmolecule-mediated endocytosis.

In vitro competition experiments showed that the association of aICAM-1 L with ICAM-1 on endothelial cells was lowered in the presence of leukocytes (Figure $5 \mathrm{~d}$ ). This is probably related to occupation and steric hindrance of ICAM-1 receptors by the CD11b/CD18-expressing leukocytes. In vivo, partial blocking of ICAM-1 receptors on inflamed endothelium by leukocytes could result in an underestimation of the ICAM-1 expression level by aICAM-1 L. Moreover, both aICAM-1 L and IgG L were internalized by phagocytotic leukocytes in vitro (Figure 5e). This might cause false positive non-specific MR-signal enhancement in vivo by extravasation of liposome-laden leukocytes at sites of inflammation. Nevertheless, in the circulation quiescent leukocytes require activation by local inflammatory stimuli and therefore blood-pool accumulation of liposomes in leukocytes is expected to be low.

The capacity of aICAM-1 L to bind to endothelial cells lining the vasculature could be affected by blood flow, which reduces the interaction time for liposome binding and imposes torque and shear forces on the adherent liposomes, as was previously observed for targeted fluorescent microbeads and ultrasound microbubbles [10,11,34-36]. In this study, in vitro binding of aICAM-1 L to ICAM-1 was reduced with increasing shear stress within a physiologically relevant range (Figure 6b) [12]. Nevertheless, the ability of aICAM-1 L to bind to endothelial cells in the microcirculation in vivo might be improved by the effect that erythrocytes preferentially occupy the center of blood vessels, thereby increasing the effective liposome concentration near the vessel wall and enhancing their probability to interact with the endothelium [37]. Furthermore, there are several options to improve the binding of aICAM-1 L to endothelial cells. Recently, Calderon et al. observed improved interaction kinetics and total bond strength of ICAM-1-targeted microbeads with endothelial 
cells, when increasing the nanoparticle's antibody density from $1100 \mathrm{Ab} / \mu \mathrm{m}^{2}$ to $4100 \mathrm{Ab} / \mu \mathrm{m}^{2}$ [11]. This is probably related to an increased multivalency of nanoparticleendothelial cell interactions. Furthermore, incorporation of PEG-polymers in the liposome bilayer, as used in our liposome formulation, may have a positive effect on the aICAM-1/ICAM-1 interaction strength. PEG is capable of enhancing the bond lifetime between ligands on nanoparticles and their corresponding receptors on cells under hydrodynamic conditions by increasing the bond flexibility [38]. Moreover, liposomes might be functionalized with more than one type of targeting ligand to optimize endothelial cell association under flow conditions, as previously shown for VCAM-1 and P-selectin targeted microbubbles by Ferrante et al. [26,39].

\section{Conclusions}

In this study, a high-relaxivity ICAM-1-binding liposomal MR-contrast agent was developed that 1) showed strong binding to endothelial cells that depended on both the ICAM-1 expression level and the concentration of liposomes, 2) could distinguish between basal and upregulated levels of ICAM-1 expression by MRI and 3) displayed significant binding to endothelial ICAM-1 even in the competing presence of leukocytes and under physiological flow conditions. Taken together, the ability of ICAM-1 targeted liposomes to bind ICAM-1 under these harsh conditions might allow this contrast agent to visualize ICAM-1 in a variety of cardiovascular and neurological diseases using in vivo MR-imaging.

\section{Methods}

\section{Liposome preparation}

Liposomes were composed of 1,2-distearoyl-sn-glycero -3-phosphocholine (DSPC, Lipoid, Steinhausen, Switzer land), cholesterol (Avanti Polar Lipids, Alabaster, USA), gadolinium-DOTA-1,2-distearoyl-sn-glycero-3-phosphoe thanolamine (Gd-DOTA-DSPE, SyMO-Chem, Eindhoven, the Netherlands), DSPE- $N$-[methoxy(poly(ethyleneglycol))2000] (PEG-DSPE, Lipoid), DSPE- $N$-[maleimide I(poly(ethyleneglycol))2000] (Mal-PEG-DSPE, Avanti Polar Lipids) and near-infrared664-DSPE (NIR664-DSPE, SyMOChem) or 1,2-dipalmitoyl-sn-glycero-3-phosphoethanolamine- $N$-(lissamine rhodamine B sulfonyl) (rhodamine-PE, Avanti Polar Lipids) in a molar ratio of 1.1:1:0.75:0.075:0 .075:0.003. Lipid films were prepared by rotary evaporation $\left(30{ }^{\circ} \mathrm{C}\right)$ of $50 \mu \mathrm{mol}$ lipid dissolved in chloroform and methanol $(8: 1 \mathrm{v} / \mathrm{v})$, with additional drying under $\mathrm{N}_{2}$. To obtain liposomes, lipid films were hydrated at $65{ }^{\circ} \mathrm{C}$ for $10 \mathrm{~min}$ in $8 \mathrm{ml}$ HEPES-buffered saline (HBS, pH 6.7), composed of $10 \mathrm{mM}$ HEPES and $135 \mathrm{mM} \mathrm{NaCl}$, followed by extrusion at $65{ }^{\circ} \mathrm{C}$ through polycarbonate membrane filters of $400 \mathrm{~nm}(2 \mathrm{x})$ and $200 \mathrm{~nm}(10 \mathrm{x})$ [23].

\section{Liposome functionalization with antibodies}

Monoclonal mouse aICAM-1 and isotype-matched control IgG antibodies (clone YN1/1.7.4 and RTK4530, BioLegend, Uithoorn, the Netherlands) were covalently coupled to MalPEG-DSPE through thioether linkage to obtain aICAM-1 liposomes (aICAM-1 L) and IgG liposomes (IgG L), respectively [40]. For this purpose, acetylthioacetate moieties were introduced on antibodies by modification with $\mathrm{N}$-succinimidyl $S$ acetylthioacetate (SATA, Sigma-Aldrich, Zwijndrecht, the Netherlands) for $40 \mathrm{~min}$ at room temperature (RT). Various molar ratios of Ab:SATA (1:8, 1:20, 1:40 and 1:80) were tested to optimize antibody coupling to liposomes. Free SATA was removed by washing in HBS ( $\mathrm{pH}$ 6.7) on a Vivaspin concentrator $\left(30 \mathrm{kDa}\right.$ cut-off) by centrifugation at $3000 \mathrm{~g}$ and $4{ }^{\circ} \mathrm{C}$. Acetylthioacetate groups were converted into free thiols by deacetylation with hydroxylamine (pH 7.0) for $1 \mathrm{~h}$ (RT). Directly thereafter, antibodies and liposomes were mixed at $50 \mu \mathrm{g}$ protein $/ \mu \mathrm{mol}$ lipid at $4{ }^{\circ} \mathrm{C}$ under $\mathrm{N}_{2}$. Coupling of the antibodies to liposomes continued overnight, after which the liposomes were diluted in HBS ( $\mathrm{pH}$ 7.4). Liposomes were separated from non-conjugated antibodies by ultracentrifugation $\left(55,000 \mathrm{rpm} ; 45 \mathrm{~min} ; 4^{\circ} \mathrm{C}\right)$. Liposomes were resuspended in $\mathrm{HBS}(\mathrm{pH} 7.4)$ to a final concentration of $50-70 \mathrm{mM}$ lipid and stored at $4{ }^{\circ} \mathrm{C}$ until further use.

\section{Liposome characterization}

Liposomal phospholipid concentration was quantified with a phosphate determination according to Rouser [41]. Antibody coupling efficacy to liposomes was determined by a Lowry-based protein assay (Bio-Rad, Veenendaal, the Netherlands), corrected for the presence of lipids [42]. The average hydrodynamic number-weighted diameter and size distribution of the liposomes were estimated by DLS of a $633 \mathrm{~nm}$ laser on a Zetasizer Nano S (Malvern Instruments, Worcestershire, UK) at RT.

Liposome morphology was evaluated with cryoTEM. Samples were vitrified on carbon-coated cryoTEM grids with a vitrification robot (Vitrobot Mark III, FEI, Hillsboro, USA). Imaging was performed on a Tecnai 20 Sphera TEM instrument (FEI) equipped with a LaB6 filament $(200 \mathrm{kV})$ and Gatan cryoholder (approximately $-170{ }^{\circ} \mathrm{C}$ ) at $6500 \mathrm{x}$ magnification.

Liposomal longitudinal and transversal relaxation times $\left(\mathrm{T}_{1}\right.$ and $\mathrm{T}_{2}$ ) were determined with a 9.4 $\mathrm{T}$ horizontal bore scanner (Bruker BioSpin GmbH, Ettlingen, Germany) using a 35-mm-diameter quadrature RF-coil (Rapid Biomedical, Rimpar, Germany). $\mathrm{T}_{1}$ was obtained with an inversionrecovery segmented FLASH sequence with $\mathrm{TR}=15 \mathrm{~s}$ and $\mathrm{TI}=72.5-4792.5 \mathrm{~ms}$ (60 inversion times). For $\mathrm{T}_{2}$ measurements, a spin echo sequence was used with $T R=2 \mathrm{~s}$ and $\mathrm{TE}=9-288 \mathrm{~ms}$ (32 echoes). Quantitative $\mathrm{T}_{1}$ and $\mathrm{T}_{2}$ values were obtained by fitting the MR-data with mono-exponential relaxation curves in Mathematica 6 (Wolfram Research Eur ope, Oxfordshire, UK). Relaxivities $\left(r_{1}\right.$ and $r_{2}$ in $\mathrm{mM}^{-1} \mathrm{~s}^{-1}$ ) 
were determined from $R_{i}=R_{i, 0}+r_{i}$. $\left.G d\right]$, with $i \in\{1,2\}, R_{i}=1 /$ $\mathrm{T}_{\mathrm{i}}, \mathrm{R}_{\mathrm{i}, 0}=\mathrm{R}_{\mathrm{i}}$ of sample without liposomes and [Gd] varying from 0.01-1 mM Gd. Relaxivities are expressed in terms of Gd concentration rather than nanoparticle concentration.

\section{Cell culture}

Mouse brain endothelioma cells, bEnd.5 (European Collection of Animal Cell Cultures (ECACC)), were cultured in low glucose DMEM, supplemented with $10 \%$ fetal bovine serum (FBS) and $5 \mu \mathrm{M}$ 2-mercaptoethanol. The bEnd.5 cells display a basal expression of ICAM-1. ICAM-1 expression was upregulated by $24 \mathrm{~h}$ activation with $40 \mathrm{ng} / \mathrm{ml}$ recombinant tumor necrosis factor- $\alpha$ (TNF $\alpha$, PeproTech EC Ltd., London, UK) as shown in Additional file 3: Figure S3. Mouse leukocytes, RAW 264.7 (ECACC), were maintained in RPMI medium, containing 10\% FBS, $2 \mathrm{mM}$ L-glutamine and $10^{5}$ U/l penicillin/streptomycin. Prior to experiments, RAW cells were fluorescently labeled with $1 \mu \mathrm{M}$ calcein AM (Invitrogen, Bleiswijk, the Netherlands) for $30 \mathrm{~min}\left(37^{\circ} \mathrm{C}\right)$. Excess calcein was removed by centrifugation $(2 \times 5 \mathrm{~min}, 500 \mathrm{~g})$.

\section{Liposomal ICAM-1 binding under static conditions}

The ability of aICAM-1 L to specifically bind to non-activated and TNF $\alpha$-activated bEnd.5 cells was first investigated under static incubation conditions. To identify the liposome formulation with highest level of ICAM-1 binding, cells were incubated for $2 \mathrm{~h}$ at $37^{\circ} \mathrm{C}$ with aICAM-1 L or IgG L, prepared with various ratios of Ab:SATA, or non-functionalized liposomes $(\mathrm{L})$ at a concentration of $1 \mathrm{mM}$ lipid. Afterwards, cells were washed with medium and phosphate buffered saline (PBS) to remove non-bound liposomes. For fluorescence intensity quantification, cells were harvested with trypsin/EDTA, fixed in $4 \%$ paraformaldehyde (PFA) and stored in $0.01 \%$ sodium-azide, whereas for confocal laser scanning microscopy (CLSM) cells cultured in microscopy chambers (Ibidi GmbH, München, Germany) were fixed in 4\% PFA and stored in PBS. Prior to CLSM, cell membranes were labeled with biotin rat anti-mouse CD31 (10 $\mu \mathrm{g} / \mathrm{ml}$, BioLegend) conjugated to streptavidin-fluorescein isothiocyanate (FITC) $(5 \mu \mathrm{g} / \mathrm{ml}$, BioLegend). Cell nuclei were labeled with $0.1 \mu \mathrm{g} / \mathrm{ml}$ 4'6-diamidino-2-phenylindole dihydrochloride (DAPI, Invitrogen). In separate samples, goat antirat Alexa488 $(10 \mu \mathrm{g} / \mathrm{ml}$, Invitrogen) was added to visualize extracellularly located antibody-conjugated liposomes.

The relation between the liposome concentration in the incubation medium and the extent of liposome binding to ICAM-1 was studied at $4{ }^{\circ} \mathrm{C}$ to inhibit internalization of ICAM-1-liposome complexes. Non-activated and TNF $\alpha$ activated cells were incubated for $30 \mathrm{~min}$ at $4{ }^{\circ} \mathrm{C}$ with various concentrations of aICAM- 1 L or IgG L (0.0625-2 mM lipid). Non-bound liposomes were removed by washing and cells were processed for fluorescence intensity quantification as described above.

To determine the sensitivity of MRI to detect basal and upregulated levels of ICAM-1 expression, non-activated and TNF $\alpha$-activated cells were incubated for $2 \mathrm{~h}$ at $37^{\circ} \mathrm{C}$ with aICAM-1 L, IgG L or L (1 mM lipid). Next, cells were washed, harvested and fixed in $4 \%$ PFA. A loosely packed cell pellet was allowed to form at $4{ }^{\circ} \mathrm{C}$.

\section{Competition from leukocytes}

The binding of liposomes to endothelial cells was also evaluated in the competing presence of leukocytes by coincubation of non-activated or TNF $\alpha$-activated bEnd.5 cells $\left(2 \mathrm{~h}\right.$ at $\left.37^{\circ} \mathrm{C}\right)$ with $0,2 \times 10^{5}$ or $1 \times 10^{6}$ calcein-labeled RAW cells/ml and aICAM-1 L or IgG L (1 mM lipid). To study direct interactions of leukocytes with liposomes, RAW cells were incubated for $2 \mathrm{~h}$ at $37{ }^{\circ} \mathrm{C}$ with aICAM$1 \mathrm{~L}$ or IgG $\mathrm{L}$ ( $1 \mathrm{mM}$ lipid) in the absence of bEnd. 5 cells. After incubation, cells were washed and samples were prepared for fluorescence intensity quantification. To determine ICAM-1, CD11b and CD18 expression levels on RAW cells, cells were labeled by rat anti-mouse antibodies against ICAM-1 $(10 \mu \mathrm{g} / \mathrm{ml})$ conjugated to goat anti-rat Cy3 $(5 \mu \mathrm{g} / \mathrm{ml})$, biotin CD11b $(10 \mu \mathrm{g} / \mathrm{ml})$ in combination with streptavidin-Cy3 (5 $\mu \mathrm{g} / \mathrm{ml})$ or CD18 R-phycoerythrin (PE) $(4 \mu \mathrm{g} / \mathrm{ml})$ (all antibodies from BioLegend).

\section{Liposomal ICAM-1 binding under shear stress conditions}

The effect of shear stress on the ability of aICAM-1 L to associate with endothelial ICAM-1 was studied with a unidirectional flow system (Ibidi GmbH) [43]. The system was calibrated at a shear stress of $0.25 \mathrm{~Pa}$ and $0.5 \mathrm{~Pa}$, taking into account the viscosity of medium containing liposomes $(\eta=0.75 \mathrm{mPa} \cdot \mathrm{s}$ at both shear stress values). The bEnd. 5 cells were cultured and activated with TNF $\alpha$ on flow chamber microscopy slides (50x5x0.8 $\mathrm{mm}^{3} \mu$-slide, Ibidi $\mathrm{GmbH}$ ) under static conditions. Subsequently, TNF $\alpha$-activated bEnd. 5 cells were incubated with aICAM-1 L or L $(1 \mathrm{mM}$ lipid) at a constant shear stress of $0,0.25$ or $0.5 \mathrm{~Pa}$ in closed flow chambers at $37^{\circ} \mathrm{C}$. After $2 \mathrm{~h}$, cells were washed and the rhodamine fluorescence of adherent liposomes was evaluated with a Leica DMI 3000B microscope (Leica Microsystems, Rijswijk, Netherlands) equipped with a Leica EL6000 light source and $590 \mathrm{~nm}$ long pass filter. Afterwards, samples were prepared for fluorescence intensity quantification. To evaluate ICAM-1 expression at different flow rates, cells were labeled with rat anti-mouse ICAM-1 $(20 \mu \mathrm{g} / \mathrm{ml})$ and goat anti-rat Alexa488 $(40 \mu \mathrm{g} / \mathrm{ml})$.

\section{Cellular fluorescence intensity}

The fluorescence intensity of cell-associated rhodamineor NIR664-lipids and fluorescently labeled antibodies was quantified by FACS on a Guava EasyCyte 8HT (Millipore, Billerica, USA). NIR664 was excited with a $640 \mathrm{~nm}$ laser and detected using a $661 / 19 \mathrm{~nm}$ band pass (BP) filter. Rhodamine, Cy3 and PE were detected with a $488 \mathrm{~nm}$ laser combined with a 583/26 nm BP filter, whereas calcein-labeled RAW cells and Alexa488 were captured 
with a 525/30 BP filter. Mean cellular fluorescence intensity was determined with Kaluza 1.0 software (Beckman Coulter) and was corrected for cellular autofluorescence, unless mentioned otherwise.

\section{Cellular distribution of liposomes}

The cellular location of the liposomes was studied with CLSM. NIR664-lipids were visualized with an LSM 510 META system (Carl Zeiss B.V., Sliedrecht, Netherlands) equipped with a $633 \mathrm{~nm}$ HeNe laser $(5.0 \mathrm{~mW})$ in combination with a $680 / 60 \mathrm{~nm}$ BP filter. Cell membranes and extracellular liposomes labeled with Alexa488 were detected with a $488 \mathrm{~nm}$ argon laser $(13.5 \mathrm{~mW})$ using a 525/50 nm BP filter. A Ti:Sapphire laser tuned to $780 \mathrm{~nm}$ $(2925.0 \mathrm{~mW})$ was used for two-photon excitation of DAPI, whose fluorescence was captured with a 460/50 BP filter. All images were acquired with a $63 \mathrm{x}$ oil immersion objective at $0.07 \times 0.07 \mu^{2}$ in-plane resolution (2048x2048 matrix, 4 averages).

\section{Cellular relaxation rates and relaxivities}

Cellular relaxation rates $\left(R_{1}\right.$ and $\left.R_{2}\right)$ were determined at 9.4 $\mathrm{T}$ as described above. Cellular relaxivities $\left(r_{1}\right.$ and $\left.r_{2}\right)$ were calculated according to $R_{i}=R_{i, 0}+r_{i}$. $[G d]$, with $i \in$ $\{1,2\}, R_{i, 0}=R_{i}$ of cells incubated without liposomes. To quantify gadolinium concentrations, the volume of the cell pellets was obtained from 3D FLASH MR-images (9.4 T; $\mathrm{TR}=25 \mathrm{~ms} ; \mathrm{TE}=3.7 \mathrm{~ms}$; flip angle $=30^{\circ} ; 100 \mu \mathrm{m}^{3}$ isotropic resolution) with Osirix Software (www.osirix-viewer.com), whereas the gadolinium content was quantified by inductively coupled plasma mass spectrometry (ICP-MS) using a DRCII (Perkin Elmer, Waltham, USA) after destruction in 1:2 (v/v) nitric acid and perchloric acid at $180{ }^{\circ} \mathrm{C}$.

\section{Statistics}

One-way analysis of variance (ANOVA) with Bonferroni correction for multiple group comparisons and ANOVA with LSD correction or Student's $t$-test for comparison between two groups were used to test for significant differences $(p<0.05)$. Data were presented as mean \pm SEM.

\section{Additional files}

Additional file 1: Figure S1. CLSM images of activated bEnd.5 cells incubated with alCAM-1 L (Ab:SATA = 1:80). (left) NIR fluorescence from the liposomes in red. (middle) In green, fluorescence from extracellularly located antibodies labeled with goat anti-rat Alexa488. (right) Merged image shows the co-localization (yellow) of alCAM-1 L (red) and Alexa488- IgG (green), thereby confirming the extracellular location of alCAM-1 L. Laser power 488 nm: 3\%, 633 nm: 5\%. Scale bar $=50 \mu \mathrm{m}$.

Additional file 2: Figure S2. ICAM-1, CD11b and CD18 expression levels on RAW cells quantified with FACS. Fluorescence intensities were corrected for non-specific binding of goat anti-rat Cy3. $n=1$.

Additional file 3: Figure S3. ICAM-1 and CD31 expression levels on non-activated ( - TNFa) and activated (+TNFa) bEnd.5 cells quantified with FACS. Fluorescence intensities were corrected for non-specific binding of goat anti-rat Alexa488. The fluorescence of non-activated cells labeled with alCAM-1 antibodies did not exceed the fluorescence of cells incubated with goat anti-rat Alexa488 only. $n=3$ for ICAM-1 and $n=1$ for CD31. ${ }^{*}=p<0.05$ vs. - TNFa/ICAM-1, $t$-test.

\section{Abbreviations}

Ab: Antibody; CLSM: Confocal laser scanning microscopy; cryoTEM: Cryogenic transmission electron microscopy; DLS: Dynamic light scattering; FACS: Fluorescence activated cell sorting; ICAM-1: Intercellular adhesion molecule-1; alCAM-1: Anti-ICAM-1; ICP-MS: Inductively coupled plasma mass spectrometry; alCAM-1 L: alCAM-1 liposomes; IgG L: IgG liposomes; MRI: Magnetic resonance imaging; SATA: N-succinimidyl Sacetylthioacetate.

\section{Competing interests}

The authors declare that they have no competing interests.

\section{Authors' contributions}

All authors added intellectual content, read and approved the final version. LP: Designed the study, performed experiments, performed data analysis, performed statistical analysis, prepared and edited the manuscript. IJ, NvdA, TG, LS: Performed experiments, performed data analysis, edited the manuscript. DM: Edited the manuscript. KN: Co-designed the study, edited the manuscript. GS: Principal investigator, designed the study, prepared and edited the manuscript. All authors read and approved the final manuscript.

\section{Acknowledgments}

This work is supported by the Dutch Technology Foundation STW, applied science division of NWO and the Technology Program of the Ministry of Economic Affairs; Grant number: 07952. We thank dr. ir. Chantal N. van den Broeck for assistance with the viscosity measurements.

\section{Author details}

${ }^{1}$ Biomedical NMR, Department of Biomedical Engineering, Eindhoven University of Technology, PO Box 513, 5600 MB, Eindhoven, the Netherlands. ${ }^{2}$ Department of Cardiology, Cardiovascular Research Institute Maastricht, Maastricht University, PO Box 616, 6200 MD, Maastricht, the Netherlands. ${ }^{3}$ Department of Physiology, Cardiovascular Research Institute Maastricht, Maastricht University, PO Box 616, 6200 MD, Maastricht, the Netherlands.

Received: 19 March 2012 Accepted: 4 June 2012

Published: 20 June 2012

\section{References}

1. Glass CK, Witztum JL: Atherosclerosis: the road ahead. Cell 2001, 104:503516.

2. Frangogiannis NG, Smith CW, Entman ML: The inflammatory response in myocardial infarction. Cardiovasc Res 2002, 53:31-47.

3. Rossi B, Angiari S, Zenaro E, Budui SL, Constantin G: Vascular inflammation in central nervous system diseases: adhesion receptors controlling leukocyte-endothelial interactions. J Leukocyte Biol 2011, 89:539-556.

4. Mousa SA: Cell adhesion molecules: potential therapeutic \& diagnostic implications. Mol Biotechnol 2008, 38:33-40.

5. Johnson-Leger C, Imhof BA: Forging the endothelium during inflammation: pushing at a half-open door? Cell Tissue Res 2003, 314:93-105.

6. Auerbach SD, Yang L, Luscinskas FW: Adhesion molecules: function and inhibition. In Endothelial ICAM-1 functions in adhesion and signaling during leukocyte recruitment. Edited by Ley K. Basel: Birkhauser; 2007:99-116.

7. Lawson C, Wolf S: ICAM-1 signaling in endothelial cells. Pharmacol Rep 2009, 61:22-32.

8. Leuschner F, Nahrendorf M: Molecular imaging of coronary atherosclerosis and myocardial infarction: considerations for the bench and perspectives for the clinic. Circ Res 2011, 108:593-606.

9. van Bochove GS, Paulis LE, Segers D, Mulder WJM, Krams R, Nicolay K, Strijkers GJ: Contrast enhancement by differently sized paramagnetic MRI contrast agents in mice with two phenotypes of atherosclerotic plaque. Contrast Media Mol Imaging 2011, 6:35-45. 
10. Takalkar AM, Klibanov AL, Rychak JJ, Lindner JR, Ley K: Binding and detachment dynamics of microbubbles targeted to P-selectin under controlled shear flow. J Control Release 2004, 96:473-482

11. Calderon AJ, Muzykantov V, Muro S, Eckmann DM: Flow dynamics, binding and detachment of spherical carriers targeted to ICAM-1 on endothelial cells. Biorheology 2009, 46:323-341.

12. Lipowsky HH, Kovalcheck S, Zweifach BW: The distribution of blood rheological parameters in the microvasculature of cat mesentery. Circ Res 1978, 43:738-749

13. Nagel T, Resnick N, Atkinson WJ, Forbes Dewey C, Gimbrone MA: Shear stress selectively upregulates intercellular adhesion molecule-1 expression in cultured human vascular endothelial cells. J Clin Invest 1994, 94:885-891.

14. Tsou JK, Gower RM, Ting HJ, Schaff UY, Insana MF, Passerini AG, Simon SI: Spatial regulation of inflammation by human aortic endothelial cells in a linear gradient of shear stress. Microcirculation 2008, 15:311-323.

15. Woollard KJ, Geissmann F: Monocytes in atherosclerosis: subsets and functions. Nat Rev Cardiol 2010, 7:77-86.

16. Kukielka GL, Hawkins HK, Michael L, Manning AM, Youker K, Lane C, Entman $\mathrm{ML}$, Smith CW, Anderson DC: Regulation of intercellular adhesion molecule-1 (ICAM-1) in ischemic and reperfused canine myocardium. $J$ Clin Invest 1993, 92:1504-1516.

17. Kelly KA, Allport JR, Tsourkas A, Shinde-Patil VR, Josephson L, Weissleder R: Detection of vascular adhesion molecule- 1 expression using a novel multimodal nanoparticle. Circ Res 2005, 96:327-336.

18. Mcateer MA, Sibson NR, Von Zur Muhlen C, Schneider JE, Lowe AS, Warrick N, Channon KM, Anthony DC, Choudhury RP: In vivo magnetic resonance imaging of acute brain inflammation using microparticles of iron oxide. Nat Med 2007, 13:1253-1258

19. Jin AY, Tuor UI, Rushforth D, Filfil R, Kaur J, Ni F, Tomanek B, Barber PA: Magnetic resonance molecular imaging of post-stroke neuroinflammation with a P-selectin targeted iron oxide nanoparticle. Contrast Media Mol Imaging 2009, 4:305-311.

20. Sibson NR, Blamire AM, Bernades-Silva M, Laurent S, Boutry S, Muller RN, Styles $P$, Anthony DC: MRI detection of early endothelial activation in brain inflammation. Magn Reson Med 2004, 51:248-252.

21. Choi K-S, Kim S-H, Cai Q-Y, Kim S-Y, Kim H-O, Lee H-J, Kim E-A, Yoon S-E, Yun K-J, Yoon K-H: Inflammation-specific $T_{1}$ imaging using antiintercellular adhesion molecule 1 antibody-conjugated gadolinium diethylenetriaminepentaacetic acid. Mol Imaging 2007, 6:75-84.

22. Van Bochove GS, Chatrou ML, Paulis LE, Grull H, Strijkers GJ, Nicolay K: VCAM-1 targeted MRI for imaging of inflammation in mouse atherosclerosis using paramagnetic and superparamagnetic lipid-based contrast agents. Stockholm, Sweden: Proceedings of the 18th Annual Meeting ISMRM; 2010:1258

23. Hak S, Sanders HMHF, Agrawal P, Langereis S, Grüll H, Keizer HM, Arena F, Terreno E, Strijkers GJ, Nicolay K: A high relaxivity Gd(III)DOTA-DSPE-based liposomal contrast agent for magnetic resonance imaging. Eur J Pharm Biopharm 2009, 72:397-404

24. Strijkers GJ, Mulder WJM, Van Heeswijk RB, Frederik PM, Bomans P, Magusin PCMM, Nicolay K: Relaxivity of liposomal paramagnetic MRI contrast agents. Magn Reson Mater Phy 2005, 18:186-192.

25. Morawski AM, Winter PM, Crowder KC, Caruthers SD, Fuhrhop RW, Scott MJ, Robertson JD, Abendschein DR, Lanza GM, Wickline SA: Targeted nanoparticles for quantitative imaging of sparse molecular epitopes with MRI. Magn Reson Med 2004, 51:480-486

26. Ferrante EA, Pickard JE, Rychak J, Klibanov A, Ley K: Dual targeting improves microbubble contrast agent adhesion to VCAM-1 and Pselectin under flow. J Control Release 2009, 140:100-107.

27. Calderon AJ, Bhowmick T, Leferovich J, Burman B, Pichette B, Muzykantov V, Eckmann DM, Muro S: Optimizing endothelial targeting by modulating the antibody density and particle concentration of anti-ICAM coated carriers. J Control Release 2011, 150:37-44.

28. Bloemen $P G$, Henricks PA, van Bloois $L$, van den Tweel MC, Bloem AC, Nijkamp FP, Crommelin DJ, Storm G: Adhesion molecules: a new target for immunoliposome-mediated drug delivery. FEBS Lett 1995, 357:140144.

29. Mastrobattista E, Storm G, van Bloois L, Reszka R, Bloemen PG, Crommelin DJ, Henricks PA: Cellular uptake of liposomes targeted to intercellular adhesion molecule-1 (ICAM-1) on bronchial epithelial cells. Biochim Biophys Acta 1999, 1419:353-363.
30. Kok MB, Hak S, Mulder WJM, van der Schaft DWJ, Strijkers GJ, Nicolay K: Cellular compartmentalization of internalized paramagnetic liposomes strongly influences both $\mathrm{T}_{1}$ and $\mathrm{T}_{2}$ relaxivity. Magn Reson Med 2009, 61:1022-1032

31. Strijkers GJ, Hak S, Kok MB, Springer CS, Nicolay K: Three-compartment $T_{1}$ relaxation model for intracellular paramagnetic contrast agents. Magn Reson Med 2009, 61:1049-1058.

32. Muro S, Garnacho C, Champion JA, Leferovich J, Gajewski C, Schuchman EH, Mitragotri S, Muzykantov VR: Control of endothelial targeting and intracellular delivery of therapeutic enzymes by modulating the size and shape of ICAM-1-targeted carriers. Mol Ther 2008, 16:1450-1458.

33. Muro S, Wiewrodt R, Thomas A, Koniaris L, Albelda SM, Muzykantov VR, Koval M: A novel endocytic pathway induced by clustering endothelial ICAM-1 or PECAM-1. J Cell Sci 2003, 116:1599-1609.

34. Muro S, Dziubla T, Qiu W, Leferovich J, Cui X, Berk E, Muzykantov V: Endothelial targeting of high-affinity multivalent polymer nanocarriers directed to intercellular adhesion molecule 1.J Pharmacol Exp Ther 2006, 317:1161-1169.

35. Blackwell JE, Dagia NM, Dickerson JB, Berg EL, Goetz DJ: Ligand coated nanosphere adhesion to $\mathrm{E}$ - and P-selectin under static and flow conditions. Ann Biomed Eng 2001, 29:523-533.

36. Klibanov AL, Rychak JJ, Yang WC, Alikhani S, Li B, Acton S, Lindner JR, Ley K, Kaul S: Targeted ultrasound contrast agent for molecular imaging of inflammation in high-shear flow. Contrast Media Mol Imaging 2006, 1:259266

37. Pearson MJ, Lipowsky HH: Influence of erythrocyte aggregation on leukocyte margination in postcapillary venules of rat mesentery. Am J Physiol Heart Circ Physiol 2000, 279:H1460-H1471.

38. Ham AS, Klibanov AL, Lawrence MB: Action at a distance: lengthening adhesion bonds with poly(ethylene glycol) spacers enhances mechanically stressed affinity for improved vascular targeting of microparticles. Langmuir 2009, 25:10038-10044.

39. Eniola $\mathrm{AO}$, Hammer DA: In vitro characterization of leukocyte mimetic for targeting therapeutics to the endothelium using two receptors. Biomaterials 2005, 26:7136-7144.

40. Mulder WJM, Strijkers GJ, Griffioen AW, van Bloois L, Molema G, Storm G Koning GA, Nicolay K: A liposomal system for contrast-enhanced magnetic resonance imaging of molecular targets. Bioconjugate Chem 2004, 15:799-806.

41. Rouser G, Fleischer S, Yamamoto A: Two dimensional thin layer chromatographic separation of polar lipids and determination of phospholipids by phosphorus analysis of spots. Lipids 1970, 5:494-496.

42. Lowry OH, Rosebrough NJ, Farr AL, Randall RJ: Protein measurement with the folin phenol reagent. J Bio/ Chem 1951, 193:265-275.

43. Kotsis F, Nitschke R, Doerken M, Walz G, Kuehn EW: Flow modulates centriole movements in tubular epithelial cells. Pflug Arch Eur J Phy 2008, 456:1025-1035.

doi:10.1186/1477-3155-10-25

Cite this article as: Paulis et al.: Targeting of ICAM-1 on vascular endothelium under static and shear stress conditions using a liposomal Gd-based MRI contrast agent. Journal of Nanobiotechnology 2012 10:25.

\section{Submit your next manuscript to BioMed Central and take full advantage of:}

- Convenient online submission

- Thorough peer review

- No space constraints or color figure charges

- Immediate publication on acceptance

- Inclusion in PubMed, CAS, Scopus and Google Scholar

- Research which is freely available for redistribution 